\title{
Autologous Transplantation as Consolidation for Aggressive Non-Hodgkin's Lymphoma
}

\author{
Patrick J. Stiff, M.D., Joseph M. Unger, Ph.D., James R. Cook, M.D., Ph.D., Louis S. \\ Constine, M.D., Stephen Couban, M.D., Douglas A. Stewart, M.D., Thomas C. Shea, M.D., \\ Pierluigi Porcu, M.D., Jane N. Winter, M.D., Brad S. KahI, M.D., Thomas P. Miller, M.D., \\ Raymond R. Tubbs, D.O., Deborah Marcellus, M.D., Jonathan W. Friedberg, M.D., Kevin P. \\ Barton, M.D., Glenn M. Mills, M.D., Michael LeBlanc, Ph.D., Lisa M. Rimsza, M.D., Stephen \\ J. Forman, M.D., Richard I. Fisher, and M.D \\ Loyola University Medical Center, Maywood, IL (P.J.S., K.P.B.); Southwest Oncology Group \\ Statistical Center, Fred Hutchinson Cancer Research Center, Seattle (J.M.U., M.L.); Cleveland \\ Clinic, Cleveland (J.R.C., R.R.T.); University of Rochester, Rochester, NY (L.S.C., J.W.F., R.I.F.); \\ Queen Elizabeth II Health Sciences Centre and Dalhousie University, Halifax, NS (S.C.), \\ University of Calgary-Tom Baker Cancer Centre, Calgary, AB (D.A.S.), and Margaret and \\ Charles Juravinski Cancer Centre, Hamilton, ON (D.M.) - all in Canada; University of North \\ Carolina at Chapel Hill, Chapel Hill (T.C.S.); Ohio State University Medical Center, Columbus \\ (P.P.); Northwestern University, Chicago (J.N.W.); University of Wisconsin, Madison (B.S.K.); \\ University of Arizona, Tucson (T.P.M., L.M.R.); Louisiana State University Health Sciences \\ Center, Shreveport (G.M.M.); City of Hope Medical Center, Duarte, CA (S.J.F.); and Fox Chase \\ Cancer Center-Temple Health, Temple University School of Medicine, Philadelphia (R.I.F.)
}

\begin{abstract}
Background-The efficacy of autologous stem-cell transplantation during the first remission in patients with diffuse, aggressive non-Hodgkin's lymphoma classified as high-intermediate risk or high risk on the International Prognostic Index remains controversial and is untested in the rituximab era.
\end{abstract}

\begin{abstract}
Methods-We treated 397 patients who had disease with an age-adjusted classification of high risk or high-intermediate risk with five cycles of cyclophosphamide, doxorubicin, vincristine, and prednisone (CHOP) or $\mathrm{CHOP}$ plus rituximab. Patients with a response were randomly assigned to
\end{abstract}

\footnotetext{
Copyright (C) 2013 Massachusetts Medical Society.

Address reprint requests to: Dr. Stiff at Loyola University Medical Center, 2160 S. First. Ave., Maywood, IL 60153.

Dr. Porcu reports receiving consulting fees from Hospira and Medicis, lecture fees from Physician Education Resources, honoraria from Easton Associates, ClearView Health Care Partners, and E Squared Communications, and grant support through his institution from Millennium. Dr. Kahl reports receiving payment for board membership from Roche, Seattle Genetics, Millennium, and Cell Therapeutics and consulting fees from Genentech and Celgene. Dr. Miller reports receiving grant support through his institution from Spectrum, Celgene, and Abbott. Dr. Tubbs reports receiving lecture fees from Ventana Medical Systems and grant support through his institution from Ventana Medical Systems and Abbott Molecular Vysis. Dr. Friedberg reports receiving consulting fees from Genentech, Lilly, and Trubion. Dr. LeBlanc reports holding a pending patent regarding the uses of diffuse large-B-cell lymphoma markers. Dr. Rimsza reports receiving lecture fees from Ventana Medical Systems, and grant support through her institution from Ventana Medical Systems, Spectrum Pharmaceuticals, and Merck. Dr. Fisher reports receiving consulting fees from Micromet, Bio Linx, Boehringer Ingelheim, Roche, and Pfizer. No other potential conflict of interest relevant to this article was reported. Disclosure forms provided by the authors are available with the full text of this article at NEJM.org.
} 
receive three additional cycles of induction chemotherapy (control group) or one additional cycle of induction chemotherapy followed by autologous stem-cell transplantation (transplantation group). The primary efficacy end points were 2-year progression-free survival and overall survival.

Results-Of 370 induction-eligible patients, 253 were randomly assigned to the transplantation group (125) or the control group (128). Forty-six patients in the transplantation group and 68 in the control group had disease progression or died, with 2-year progression-free survival rates of 69 and 55\%, respectively (hazard ratio in the control group vs. the transplantation group, 1.72; 95\% confidence interval $[\mathrm{CI}], 1.18$ to $2.51 ; \mathrm{P}=0.005)$. Thirty-seven patients in the transplantation group and 47 in the control group died, with 2-year overall survival rates of 74 and $71 \%$, respectively (hazard ratio, $1.26 ; 95 \% \mathrm{CI}, 0.82$ to $1.94 ; \mathrm{P}=0.30$ ). Exploratory analyses showed a differential treatment effect according to risk level for both progression-free survival ( $\mathrm{P}=0.04$ for interaction) and overall survival ( $\mathrm{P}=0.01$ for interaction). Among high-risk patients, the 2-year overall survival rate was $82 \%$ in the transplantation group and $64 \%$ in the control group.

Conclusions-Early autologous stem-cell transplantation improved progression-free survival among patients with high-intermediate-risk or high-risk disease who had a response to induction therapy. Overall survival after transplantation was not improved, probably because of the effectiveness of salvage transplantation.

Autologous stem-cell transplantation has long been known to improve both progression-free survival and overall survival among patients with diffuse, aggressive non-Hodgkin's lymphoma in second remission. ${ }^{1}$ When it became possible to identify patients at diagnosis who have less than a 50\% chance of sustained remission, as defined by the International Prognostic Index ${ }^{2}$ (IPI) (see Table S1 in the Supplementary Appendix, available with the full text of this article at NEJM.org), trials of up-front transplantation in this group were conducted. In the first trial, LNH-87, patients received fullcourse induction chemotherapy, regardless of their IPI risk category; those with a complete response were randomly assigned to transplantation or consolidation chemotherapy. ${ }^{3}$ Although a survival advantage was not seen with transplantation, a retrospective subgroup analysis showed improved progressionfree survival and overall survival among patients with high-intermediate-risk or high-risk disease. $^{3}$

Results of phase 2 trials suggested a benefit of consolidative transplantation in high-risk groups ${ }^{4,5}$; however, few of the subsequent phase 3 trials showed a benefit. ${ }^{6-14}$ Numerous factors complicated interpretation of the results of these trials, including insufficient sample size as a result of high dropout rates, which were due to early disease progression or a patient's decision to decline treatment, as well as trial designs that differed from that of LNH-87. Thus, 15 years after the first description of a potential benefit of consolidative transplantation in high-risk disease, no role for this treatment has been clearly established.

Given the limitations in comparing data from previous trials because of differences in study design, we evaluated the efficacy of autologous stem-cell transplantation using a design similar to that of LNH-87. Patients with high-intermediate-risk or high-risk disease who had a response to five cycles of cyclophosphamide, doxorubicin, vincristine, and prednisone (CHOP) induction chemotherapy were randomly assigned either to one additional cycle of 
induction chemotherapy plus transplantation or to three additional cycles of induction chemotherapy. Patients with early disease progression and patients who elected not to undergo transplantation did not proceed to the randomization stage of the study, which minimized dropout. Patients in the control group who had a relapse were encouraged to undergo salvage transplantation so that the efficacy of early versus delayed transplantation strategies could be evaluated.

After about one third of the patients had been enrolled, it became clear that CHOP plus rituximab (R-CHOP) was superior to $\mathrm{CHOP}$ alone as induction therapy for patients with CD20+ disease. ${ }^{15,16}$ Therefore, as of April 2003, R-CHOP was used for this subgroup.

\section{Methods}

\section{Study Design, Patients, and Oversight}

This randomized intergroup trial (Southwest Oncology Group [SWOG] trial 9704), conducted at 40 sites, was led by SWOG and included the Eastern Cooperative Oncology Group, Cancer and Leukemia Group B, and the Canadian NCIC Clinical Trials Group. Eligible patients were 15 to 65 years of age and had biopsy-confirmed non-Hodgkin's lymphoma in Working Formulation groups $\mathrm{D}$ through $\mathrm{H}$ and $\mathrm{J}$, which includes follicular large-cell, diffuse small-cleaved-cell, diffuse mixed small-cell and large-cell, diffuse largecell, large-cell immunoblastic, and small non-cleaved-cell Burkitt's and non-Burkitt's lymphoma; lymphoblastic, transformed, and mantle-cell histologic types were excluded. All patients were in an age-adjusted high-intermediate-risk or high-risk group defined by the IPI. Central pathological review was performed to determine eligibility, and a final diagnosis was issued on the basis of the 2008 World Health Organization criteria. ${ }^{17} \mathrm{~A}$ patient could be enrolled at any time before the second cycle of induction chemotherapy; patients with a response were randomly assigned to a study group after five cycles of induction. Enrollment began on August 15, 1999, and concluded on December 15, 2007, when the enrollment goal was reached.

The trial was designed by the leadership of the lymphoma committees of the U.S. and Canadian cooperative groups and was approved by the National Cancer Institute. The data were gathered and analyzed by the SWOG Statistical Center and reviewed by all the authors. The first draft of the manuscript was written exclusively by the first author. All authors reviewed the manuscript, made the decision to submit it for publication, and vouch for the completeness and accuracy of the data and analysis. No one who is not listed as an author contributed to the writing of the manuscript. The complete protocol and its amendments are available at NEJM.org. Bristol-Myers Squibb provided unrestricted capitation payments to the enrolling sites to cover expenses associated with the trial for the study participants, but they had no role in data collection or analysis or in manuscript preparation.

The study was performed in accordance with the Declaration of Helsinki and Good Clinical Practice guidelines and was approved by the local institutional review board at each participating site. Patients were required to provide written informed consent before enrollment. 


\section{Treatment Plan}

Stratification was performed on the basis of the IPI risk category. Patients were treated with five cycles of induction chemotherapy with CHOP or R-CHOP administered every 3 weeks; patients with at least a partial response after cycle 5 were randomly assigned to receive either three additional cycles of induction chemotherapy (control group) or a single cycle followed by autologous stem-cell transplantation (transplantation group) (Fig. S1 in the Supplementary Appendix). R-CHOP was used in place of CHOP in patients with CD20+ disease, starting in April 2003 (two thirds of patients were enrolled after this date). Patients assigned to transplantation underwent total-body irradiation (12 Gy in eight 1.5 -Gy fractions twice daily on days -8 through -5 ) or received high-dose carmustine (300 $\mathrm{mg}$ per square meter of body-surface area) on day -6 with high-dose etoposide (60 mg per kilogram of adjusted ideal body weight) given on day -4 and high-dose cyclophosphamide (100 mg per kilogram of ideal body weight) given on day $-2 \cdot{ }^{17}$ The decision to use total-body irradiation was made by the site investigators. All patients 60 years of age or older received the carmustine-based regimen; all patients younger than 60 years of age at a given institution either underwent total-body irradiation or received the carmustine-based regimen, in accordance with institutional preference. Transplantation occurred on day 0 ; decisions about supportive care were made by the site investigators.

After completion of the study treatment, disease evaluation, consisting of physical examinations conducted at least quarterly and computed tomographic scanning conducted quarterly, was performed over a period of 2 years, beginning on day 60. No additional therapy (including additional radiotherapy) was permitted unless it was for biopsyconfirmed residual or progressive disease. Treatment responses were documented as previously reported. ${ }^{18}$

\section{Statistical Analysis}

The objectives of the study were to compare progression-free survival and overall survival, within a modified intention-to-treat design, among all eligible patients who were randomly assigned to a treatment group. The sample size was chosen under the assumption of a 2-year overall survival rate of $60 \%$ in the control group; a hazard ratio of 1.5 corresponded to a 2year survival rate of $71 \%$ in the transplantation group. We calculated that a sample of 270 eligible patients randomly assigned to a treatment group over a period of 5 years, with 2 years of additional follow-up, would be required for a power of 0.82 to detect a hazard ratio of 1.5 (control group vs. transplantation group), with the use of a log-rank test and a onesided alpha level of 0.05 , assuming exponential survival distributions. We assumed that $25 \%$ of patients would not reach the randomization stage as a result of ineligibility, the patient's decision not to proceed to the randomization stage of the study, or early disease progression; thus, it was estimated that 360 patients would need to be registered in order for 270 eligible patients to be assigned to a treatment group. Under the assumption of a 2-year progressionfree survival rate of 55\% in the control group, a hazard ratio of 1.5 corresponded to a 2-year progression-free survival rate of $67 \%$ in the transplantation group. All $\mathrm{P}$ values are based on twosided tests unless stated otherwise. 


\section{Results}

\section{Characteristics of the Patients}

A total of 397 patients were registered (Fig. 1). Of the 370 who were eligible for inclusion, 117 did not proceed to the randomization stage of the study, in most cases because of early disease progression (66 patients, 56\%) or the patient's decision to decline randomization (23 patients, 20\%). Of the 253 patients randomly assigned to a treatment group, 128 were assigned to the control group and 125 to the transplantation group.

The characteristics of the 370 eligible patients are shown in Table 1. Forty-seven percent of patients with B-cell non-Hodgkin's lymphoma received R-CHOP as induction therapy. Once rituximab was included, no patient who received CHOP induction therapy for B-cell nonHodgkin's lymphoma received R-CHOP after randomization. There were no significant differences between the randomized groups with respect to age, sex, risk group, initial stage, lactate dehydrogenase level, number of extranodal sites, or B symptoms (i.e., weight loss, night sweats, and fever) (Table S2 in the Supplementary Appendix). The proportion of patients with B-cell non-Hodgkin's lymphoma who received R-CHOP as induction therapy was higher among patients assigned to randomized treatment groups $(60 \%)$ than among all registered patients (47\%), indicating a higher dropout rate among those who received CHOP induction therapy.

\section{Toxic Effects}

During the first five cycles of CHOP or R-CHOP, there were four deaths; three were due to neutropenic infections, and one was due to hemorrhage. As expected, a markedly greater number of grade 3 and grade 4 toxic effects was seen among patients randomly assigned to transplantation (Table 2). In this group, six patients (5\%) died from toxic effects: three as a result of lung damage, and one each as a result of hemorrhage and renal failure, infection, and multiorgan failure. In the control group, three patients (2\%) died, one each as a result of cardiovascular toxic effects, infection, and unknown factors.

\section{Outcomes}

After randomization, nine patients (7\%) randomly assigned to transplantation did not undergo the procedure: six $(5 \%)$ because they decided against it and one each because of unsuccessful mobilization of stem cells, early disease progression, and early death. Of the six patients who declined transplantation, three did not have a relapse and two had a relapse (one died from the relapse, and one underwent salvage transplantation and survived); the sixth patient reversed the initial decision and underwent transplantation. In the control group, two patients (2\%) received no further chemotherapy, and one received rituximab mono-therapy.

Forty-six of the 125 patients in the transplantation group and 68 of the 128 patients in the control group had disease progression or died. The estimated 2-year progression-free survival rate was $69 \%$ in the transplantation group and $55 \%$ in the control group (Fig. 2). In a multivariate Cox regression model with adjustment for the risk score, the hazard ratio for progression or death in the control group versus the transplantation group was 1.72 (95\% 
confidence interval $[\mathrm{CI}], 1.18$ to $2.51 ; \mathrm{P}=0.005 ; \mathrm{P}=0.002$ in a one-sided test). Median progression-free survival from initial registration was not reached in the transplantation group and was 2.8 years in the control group.

Thirty-seven of the 125 patients in the transplantation group and 47 of the 128 patients in the control group died, at a median follow-up of 6.3 years. The estimated 2-year overall survival rate was $74 \%$ in the transplantation group and $71 \%$ in the control group (Fig. 2). In a multivariate Cox regression with adjustment for the risk score, the hazard ratio for death in the control group versus the transplantation group was 1.26 (95\% CI, 0.82 to $1.94 ; \mathrm{P}=0.30$; $\mathrm{P}=0.15$ in a one-sided test). Median overall survival from initial registration was not reached for either group. The 9 patients assigned to transplantation who did not undergo the procedure had a 2-year progression-free survival rate of 56\% (95\% CI, 23 to 88) and an overall survival rate of $78 \%$ (95\% CI, 51 to 100). Results for the main effect of treatment were similar among all patients who underwent randomization, and there was no evidence that treatment patterns differed according to receipt or nonreceipt of rituximab (data not shown).

In the control group, there were 11 second cancers in 10 patients: skin cancer (4 cases), breast cancer (2), follicular non-Hodgkin's lymphoma (1), acute myeloid leukemia (1), prostate cancer (1), multiple myeloma (1), and adenocarcinoma with unknown primary site (1). In the transplantation group, there were 12 second cancers in 11 patients: skin cancer (3 cases), renal cancer (3), thyroid cancer (2) myelodysplastic syndrome (1), breast cancer (1), cervical cancer (1), and lung cancer (1). Progression-free survival, overall survival, second primary cancers, and toxic effects of treatment were also analyzed according to the preparative regimen. In the comparison of preparative regimens, there was no significant difference in progression-free survival or overall survival between patients receiving carmustine and patients receiving total-body irradiation $(\mathrm{P}=0.51$ for progression-free survival and $\mathrm{P}=0.64$ for overall survival). The incidence of second cancers was also similar between patients receiving carmustine and patients receiving total-body irradiation (11\% and $5 \%$, respectively), as were the proportions of patients with grade 5 toxic effects (6\% and $5 \%$ ) and the proportions with grade 4 or 5 toxic effects ( $81 \%$ and $80 \%$ ).

\section{Treatment Effect in Subgroups}

Among the patients who underwent randomization, the IPI risk category distributions were similar among the 150 patients with B-cell lymphoma treated with R-CHOP (36\% were at high risk), the 75 patients with B-cell lymphoma treated with CHOP (32\% were at high risk), and the 28 patients with T-cell lymphoma (36\% were at high risk). No differential treatment effect (i.e., statistical interaction) was noted between the subset of patients with Bcell lymphoma and the subset of patients with T-cell lymphoma, for either progression-free survival $(\mathrm{P}=0.46)$ or overall survival $(\mathrm{P}=0.56)$. In the subgroup of patients with $\mathrm{B}$-cell lymphoma, the treatment effects on progression-free survival and overall survival were similar to those in the primary analysis; the hazard ratio for progression or death was 1.84 (95\% CI, 1.22 to $2.78 ; \mathrm{P}=0.004)$, and the hazard ratio for death was 1.36 (95\% CI, 0.85 to $2.20 ; \mathrm{P}=0.21)$. In this subgroup, the treatment effect also did not differ significantly between patients treated with R-CHOP and patients treated with CHOP, for either 
progression-free survival $(\mathrm{P}=0.33)$ or overall survival $(\mathrm{P}=0.31)$. Among patients with $\mathrm{B}$ cell lymphoma who were treated with R-CHOP, the estimated 2-year progression-free survival rate was $73 \%$ in the transplantation group and $63 \%$ in the control group (hazard ratio for progression or death, $1.56 ; 95 \% \mathrm{CI}, 0.92$ to $2.63 ; \mathrm{P}=0.10 ; \mathrm{P}=0.05$ in a one-sided test); the estimated 2-year overall survival rate was $77 \%$ in the transplantation group and $73 \%$ in the control group (hazard ratio for death, $1.09 ; 95 \% \mathrm{CI}, 0.59$ to $2.00 ; \mathrm{P}=0.79 ; \mathrm{P}=$ 0.39 in a one-sided test).

The treatment effect did differ between high-risk patients and high-intermediate-risk patients for both progression-free survival $(\mathrm{P}=0.04$ for interaction) and overall survival $(\mathrm{P}=0.01$ for interaction). In the subset of 165 high-intermediate-risk patients, the 2-year progressionfree survival rate was $66 \%$ among patients in the transplantation group and $63 \%$ among patients in the control group $(\mathrm{P}=0.32)$; in the subset of 88 high-risk patients, the 2-year progression-free survival rates were $75 \%$ and $41 \%$, respectively $(\mathrm{P}=0.001)$ (Fig. 3). The estimated overall survival rates for high-intermediate-risk patients in the transplantation and control groups were $70 \%$ and $75 \%$, respectively $(\mathrm{P}=0.48)$, and those for high-risk patients were $82 \%$ and $64 \%(\mathrm{P}=0.01)$. Subset $\mathrm{P}$ values were unplanned, and no adjustments were made for multiple comparisons. In the subset of patients with B-cell lymphoma, similar patterns were observed for both progression-free survival ( $\mathrm{P}=0.05$ for interaction) and overall survival ( $\mathrm{P}=0.03$ for interaction).

\section{Treatment after Relapse}

Of the 128 patients randomly assigned to the control group, 62 (48\%) had a relapse. Twentynine (47\%) of these patients underwent salvage chemotherapy and transplantation, $11(38 \%)$ of whom survived without disease progression. An additional 7 patients survived without progression after alternative salvage therapy. In total, 18 (29\%) of the 62 patients in the control group who had a relapse survived without disease.

Of the 28 patients in the transplantation group who had a relapse (median time to relapse, 6 months), 23 (82\%) died, most after salvage chemoimmunotherapy failed to induce a second remission. Allogeneic stem-cell transplantation was performed in 3 patients, 2 of whom died from toxic effects, and 1 of whom had a subsequent relapse but was alive at the time of writing.

\section{Discussion}

Numerous phase 3 trials of up-front autologous stem-cell transplantation have not validated a survival benefit in high-risk patients, but the negative outcome in these trials was often influenced by the study design; patients were usually randomly assigned to a treatment group at diagnosis, and approximately $15 \%$ did not receive the assigned therapy because of early progression ${ }^{19}$ and as many as one third of those assigned to transplantation declined it. ${ }^{6-14}$ Our study mirrored the LNH-87 trial design; as a result, the dropout rate was greatly reduced, with only $5 \%$ of patients assigned to the transplantation group declining the procedure. Like many of the randomized trials and several meta-analyses, ${ }^{20,21}$ our study showed an improvement in progression-free survival for the combined high-risk and highintermediate-risk groups but no improvement in overall survival, probably because $29 \%$ of 
patients who had a relapse or progression after standard therapy had long-term progressionfree survival after salvage therapy that often included transplantation. The outcomes were similar for patients with T-cell disease and those with B-cell disease, and among patients with B-cell disease, the results were similar for those treated with R-CHOP and those treated with $\mathrm{CHOP}$ alone. In addition, we saw no increase in the number of late complications, including treatment-related myeloid cancers, in patients who underwent transplantation, as compared with those in the control group, probably because of the timing of transplantation in this study.

The difference in progression-free and overall survival between the transplantation group and the control group was especially pronounced among patients in the high-risk subgroup. Although this finding has some credibility because the patients in the trial were stratified according to risk, this analysis was not preplanned, and the study was not powered to address this subgroup-related question. Thus, the finding needs to be verified prospectively, although undertaking such a trial would be difficult, given the small fraction of patients presenting with high-risk disease. However, the results of our analysis, as well as those of phase 2 transplantation trials, in which the 4-year progression-free survival rates among patients with high-risk disease ranged from 64 to $78 \%$ after treatment with a rituximabbased induction regimen, ${ }^{22-27}$ compare favorably to the $50 \%$ progression-free survival rate after treatment with R-CHOP alone ${ }^{28}$ suggesting that early transplantation may be warranted in high-risk disease.

Advancements in the diagnosis and management of diffuse, aggressive non-Hodgkin's lymphoma since the initiation of our study could make transplantation decision-making more clear-cut. Although it was not the standard of care during trial enrollment, ${ }^{18} \mathrm{~F}$ fluorodeoxyglucose with positron-emission tomography (FDG-PET) might have been useful in identifying transplantation candidates after five cycles of CHOP or R-CHOP or an even shorter induction regimen, because a positive scan does predict outcome when a regimen of either duration is used. ${ }^{29-31}$ Treatment modifications have also been explored. Although pilot studies suggested a benefit of dose-dense induction regimens, phase 3 trials have not shown that they are superior to the standard 3-week R- CHOP regimen. ${ }^{32-34}$ However, combining intensive, non-cross-resistant regimens as induction therapy in high-risk populations appears to have promising results. Moskowitz and colleagues treated 98 patients with four cycles of dose-dense R-CHOP followed by three cycles of ifosfamide, carboplatin, and etoposide, reserving transplantation for the 5\% of patients who had FDG-PET-positive and biopsy-positive disease after R-CHOP induction therapy. ${ }^{35}$ They reported a 79\% progression-free survival rate among their patients, $79 \%$ of whom were in the same highintermediate-risk and high-risk groups as the patients in our study. It is notable that 7 of the 12 patients with a relapse who did not initially undergo transplantation had a second complete response after salvage transplantation, which yielded a $90 \%$ overall survival rate.

Finally, although advances in defining adverse molecular abnormalities could, in theory, be used to select patients for consolidative transplantation, it is unlikely that the overall outcomes would improve for patients with these types of lymphoma. In particular, adverse outcomes for patients with "double-hit" lymphomas (tumors with both MYC and BCL2 translocations) have been described, with some studies suggesting that transplantation be 
used for patients with a treatment response. ${ }^{36,37}$ This subgroup of diffuse, aggressive nonHodgkin's lymphoma accounts for 3 to 5\% of all B-cell non-Hodgkin's lymphoma and is associated with high-risk clinical features and central nervous system involvement. Given the low incidence of this type of lymphoma and the frequent early failure of standard therapy, typically before the timing of randomization in our trial, a transplantation benefit is unlikely; in fact, data now suggest that autologous and even allogeneic transplants fail to improve the dismal prognosis for patients in this subgroup. ${ }^{38}$ However, patients with intermediate-grade non-Hodgkin's (and non-Burkitt's) lymphoma with $M Y C$ positivity alone also have an adverse prognosis, as confirmed by a preliminary analysis of data from the current trial, ${ }^{39}$ and such patients may benefit from transplantation. Because the percentage of such patients is small, however, prospective validation of transplantation in a randomized trial is unlikely.

In conclusion, although we found that progression-free survival was superior with early transplantation among patients with high-intermediate-risk or high-risk non-Hodgkin's lymphoma who had a response to induction therapy, we could not validate a benefit of consolidative transplantation with respect to overall survival, probably because of the effectiveness of salvage transplantation in the control group. Thus, early transplantation and late transplantation achieve roughly equivalent overall survival in the combined risk groups. Early transplantation appears to be beneficial for the small group of patients presenting with high-risk disease.

\section{Supplementary Material}

Refer to Web version on PubMed Central for supplementary material.

\section{Acknowledgments}

Supported in part by Public Health Service Cooperative Agreement grants from the National Cancer Institute, Department of Health and Human Services (CA32102, CA38926, CA11083, CA46282, CA58658, CA13612, CA45377, CA35431, CA76448, CA46441, CA35261, CA20319, CA22433, CA58416, CA46113, CA63844, CA35090, CA63845, CA76447, CA04919, CA35178, CA35281, CA14028, CA46368, CA67575, CA45560, CA58686, CA52654, CA58861, CA35192, CA76132, CA37981, CA12644, CA27057, CA077202, CA047559, CA077658, CA17145, CA21076, and CA21115); by grants from the Canadian Cancer Society Research Institute (021039 and 015469); and in part by Bristol-Myers Squibb.

Funded by the National Cancer Institute, Department of Health and Human Services, and others; SWOG-9704 ClinicalTrials.gov number, NCT00004031.

\section{References}

1. Philip T, Guglielmi C, Hagenbeek A, et al. Autologous bone marrow transplantation as compared with salvage chemotherapy in relapses of chemotherapy-sensitive non-Hodgkin's lymphoma. $\mathrm{N}$ Engl J Med. 1995; 333:1540-5. [PubMed: 7477169]

2. The International Non-Hodgkin's Lymphoma Prognostic Factors Project. A predictive model for aggressive non-Hodgkin's lymphoma. N Engl J Med. 1993; 329:987-94. [PubMed: 8141877]

3. Haioun C, Lepage E, Gisselbrecht C, et al. Survival benefit of high-dose therapy in poor-risk aggressive non-Hodgkin's lymphoma: final analysis of the prospective LNH87-2 protocol - a Groupe d'Etude des Lymphomes de l'Adulte study. J Clin Oncol. 2000; 18:3025-30. [PubMed: 10944137] 
4. Nademanee A, Molina A, O'Donnell MR, et al. Results of high-dose therapy and autologous bone marrow/stem cell transplantation during remission in poor-risk intermediated and high-grade lymphoma: International Index High and High-Intermediate Risk Group. Blood. 1997; 90:3844-52. [PubMed: 9354650]

5. Freedman AS, Takvorian T, Neuberg D, et al. Autologous bone marrow transplantation in poorprognosis intermediate-grade and high-grade B-cell non-Hodgkin's lymphoma in first remission: a pilot study. J Clin Oncol. 1993; 11:931-6. [PubMed: 8487057]

6. Verdonck LF, van Putten WLJ, Hagenbeek A, et al. Comparison of CHOP chemotherapy with autologous bone marrow transplantation for slowly responding patients with aggressive nonHodgkin's lymphoma. N Engl J Med. 1995; 332:1045-51. [PubMed: 7898521]

7. Gianni AM, Bregni M, Siena S, et al. High-dose chemotherapy and autologous bone marrow transplantation compared with MACOP-B in aggressive B-cell lymphoma. N Engl J Med. 1997; 336:1290-7. [PubMed: 9113932]

8. Milpied N, Deconinck E, Gaillard F, et al. Initial treatment of aggressive lymphoma with high-dose chemotherapy and autologous stem-cell support. N Engl J Med. 2004; 350:1287-95. [PubMed: 15044639]

9. Betticher DC, Martinelli G, Radford JA, et al. Sequential high dose chemotherapy as initial treatment for aggressive sub-types of non-Hodgkin lymphoma: results of the international randomized phase III trial (MISTRAL). Ann Oncol. 2006; 17:1546-52. [PubMed: 16888080]

10. Santini G, Salvagno L, Leoni P, et al. VACOP-B versus VACOP-B plus autologous bone marrow transplantation for advanced diffuse non-Hodgkin's lymphoma: results of a prospective randomized trial by the non-Hodgkin's Lymphoma Cooperative Study Group. J Clin Oncol. 1998; 16:2796-802. [PubMed: 9704732]

11. Gisselbrecht C, Lepage E, Molina T, et al. Shortened first-line high-dose chemotherapy for patients with poor-prognosis aggressive lymphoma. J Clin Oncol. 2002; 20:2472-9. [PubMed: 12011124]

12. Linch DC, Yung L, Smith P, et al. Final analysis of the UKLG LY02 trial comparing 6-8 cycles of CHOP with 3 cycles of CHOP followed by a BEAM autograft in patients <65 years with poor prognosis histologically aggressive NHL. Br J Haematol. 2010; 149:237-43. [PubMed: 20201949]

13. Martelli M, Gherlinzoni F, De Renzo A, et al. Early autologous stem-cell transplantation versus conventional chemotherapy as front-line therapy in high-risk, aggressive non-Hodgkin's lymphoma: an Italian multicenter randomized trial. J Clin Oncol. 2003; 21:1255-62. [PubMed: 12663712]

14. Kluin-Nelemans HC, Zagonel V, Anastasopoulou A, et al. Standard chemotherapy with or without high-dose chemotherapy for aggressive non-Hodgkin's lymphoma: randomized phase III EORTC study. J Natl Cancer Inst. 2001; 93:22-30. [PubMed: 11136838]

15. Vose JM, Link BK, Grossbard ML, et al. Phase II study of rituximab in combination with chop chemotherapy in patients with previously untreated, aggressive non-Hodgkin's lymphoma. J Clin Oncol. 2001; 19:389-97. [PubMed: 11208830]

16. Coiffier B, Lepage E, Briere J, et al. CHOP chemotherapy plus rituximab compared with CHOP alone in elderly patients with diffuse large-B-cell lymphoma. N Engl J Med. 2002; 346:235-42. [PubMed: 11807147]

17. Swerdlow, SH.; Campo, E.; Harris, NL., et al. WHO classification of tumours of hematopoietic and lymphoid tissues. 4th. Lyon, France: IARC Press; 2008.

18. Stiff PJ, Dahlberg S, Forman SJ, et al. Autologous bone marrow transplantation for patients with relapsed or refractory diffuse aggressive non-Hodgkin's lymphoma: value of augmented preparative regimens — a Southwest Oncology Group trial. J Clin Oncol. 1998; 16:48-55. [PubMed: 9440722]

19. Hitz F, Connors JM, Gascoyne RD, et al. Outcome of patients with chemotherapy refractory and early progressive diffuse large B-cell lymphoma after R-CHOP treatment. Blood. 2010; 116(1): 1751. abstract.

20. Greb A, Bohlius J, Trelle S, et al. High-dose chemotherapy with autologous stem cell support in first-line treatment of aggressive non-Hodgkin lymphoma - results of a comprehensive metaanalysis. Cancer Treat Rev. 2007; 33:338-46. [PubMed: 17400393] 
21. Greb A, Bohlius J, Schiefer D, Schwarzer G, Schulz H, Engert A. High-dose chemotherapy with autologous stem cell transplantation in the first line treatment of aggressive non-Hodgkin lymphoma (NHL) in adults. Cochrane Database Syst Rev. 2008; 1:CD004024. [PubMed: 18254036]

22. Tarella C, Zanni M, Di Nicola M, et al. Prolonged survival in poor-risk diffuse large B-cell lymphoma following front-line treatment with rituximab-supplemented, early-intensified chemotherapy with multiple autologous hematopoietic stem cell support: a multicenter study by GITIL (Gruppo Italiano Terapie Innovative nei Linfomi). Leukemia. 2007; 21:1802-11. [PubMed: 17554382]

23. Vitolo U, Chiappella A, Angelucci E, et al. Dose-dense and high-dose chemotherapy plus rituximab with autologous stem cell transplantation for primary treatment of diffuse large B-cell lymphoma with a poor prognosis: a phase II multicenter study. Haematologica. 2009; 94:1250-8. [PubMed: 19586937]

24. Dilhuydy MS, Lamy T, Foussard C, et al. Front-line high-dose chemotherapy with rituximab showed excellent long-term survival in adults with aggressive large B-cell lymphoma: final results of a phase II GOELAMS Study. Biol Blood Marrow Transplant. 2010; 16:672-7. [PubMed: 20045738]

25. Glass B, Ziepert M, Reiser M, et al. High-dose therapy followed by autologous stem-cell transplantation with and without rituximab for primary treatment of high-risk diffuse large B-cell lymphoma. Ann Oncol. 2010; 21:2255-61. [PubMed: 20444844]

26. Fitoussi O, Belhadj K, Mounier N, et al. Survival impact of rituximab combined with ACVBP panel upfront consolidation autotransplantation in high risk diffuse large B-cell lymphoma for GELA. Haematologica. 2011; 96:1136-43. [PubMed: 21546499]

27. Ziepert M, Hasenclever D, Kuhnt E, et al. Standard International Prognostic Index remains a valid predictor of outcome for patients with aggressive CD20+ B-cell lymphoma in the rituximab era. $\mathrm{J}$ Clin Oncol. 2010; 28:2373-80. Erratum, J Clin Oncol 2011;29:779. [PubMed: 20385988]

28. Spaepen K, Stroobants S, Dupont P, et al. Prognostic value of positron emission tomography (PET) with fluorine-18 fluorodeoxyglucose ([18F]FDG) after first-line chemotherapy in non-Hodgkin's lymphoma: is [18F]FDG-PET a valid alternative to conventional diagnostic methods? J Clin Oncol. 2001; 19:414-9. [PubMed: 11208833]

29. Jerusalem G, Beguin Y, Fassotte MF, et al. Persistent tumor 18F-FDG uptake after a few cycles of polychemotherapy is predictive of treatment failure in non-Hodgkin's lymphoma. Haematologica. 2000; 85:613-8. [PubMed: 10870118]

30. Spaepen K, Stroobants S, Dupont P, et al. Early restaging positron emission tomography with (18)F-fluorodeoxyglucose predicts outcome in patients with aggressive non-Hodgkin's lymphoma. Ann Oncol. 2002; 13:1356-63. [PubMed: 12196360]

31. Yang DH, Min JJ, Song HC, et al. Prognostic significance of interim ${ }^{18}$ F-FDG PET/CT after three or four cycles of R-CHOP chemotherapy in the treatment of diffuse large B-cell lymphoma. Eur $\mathrm{J}$ Cancer. 2011; 47:1312-8. [PubMed: 21334197]

32. Ohmachi K, Tobinai K, Kobayashi Y, et al. Phase III trial of CHOP-21 versus CHOP-14 for aggressive non-Hodgkin's lymphoma: final results of the Japan Clinical Oncology Group Study, JCOG 9809. Ann Oncol. 2011; 22:1382-91. [PubMed: 21196441]

33. Cunningham D, Smith P, Mouncey P, et al. R-CHOP-14 versus R-CHOP-21: results of a randomized phase III trial for the treatment of patients with newly diagnosed diffuse large B-cell non-Hodgkin's lymphoma. J Clin Oncol. 2011; 29(1):504s. abstract.

34. Schnitz N, Nickelsen M, Zepet M, et al. Conventional chemoimmunotherapy (R-CHOEP-14) or high-dose therapy (R-Mega-CHOEP) for young, high risk patients with aggressive B-cell lymphoma: final results of the randomized Mega-CHOEP trial of the Gernon High-Grade NonHodgkin's Lymphoma Study Group (DSHBHL). J Clin Oncol. 2011; 29(1):504s. abstract.

35. Moskowitz CH, Schöder H, Teruya-Feldstein J, et al. Risk-adapted dose-dense immunochemotherapy determined by interim FDG-PET in advanced-stage diffuse large B-cell lymphoma. J Clin Oncol. 2010; 28:1896-903. [PubMed: 20212248]

36. Rimsza LM, Leblanc ML, Unger JM, et al. Gene expression predicts overall survival in paraffinembedded tissues of diffuse large B-cell lymphoma treated with R-CHOP. Blood. 2008; 112:3425-33. [PubMed: 18544678] 
37. Johnson NA, Slack GW, Savage KJ, et al. Concurrent expression of MYC and BCL2 in diffuse large B-cell lymphoma treated with rituximab plus cyclophosphamide, doxorubicin, vincristine, and prednisone. J Clin Oncol. 2012; 30:3452-9. [PubMed: 22851565]

38. Aukema SM, Siebert R, Schuuring E, et al. Double-hit B-cell lymphomas. Blood. 2011; 117:2319_ 31. [PubMed: 21119107]

39. Cook JR, Goldman B, Tubbs RR, et al. MYC protein expression, but not high grade morphology is associated with poor outcome in non-Burkitt diffuse aggressive B-cell lymphomas: a SWOG 9704 correlative study. Blood. 2012; 120(1):543. abstract. 


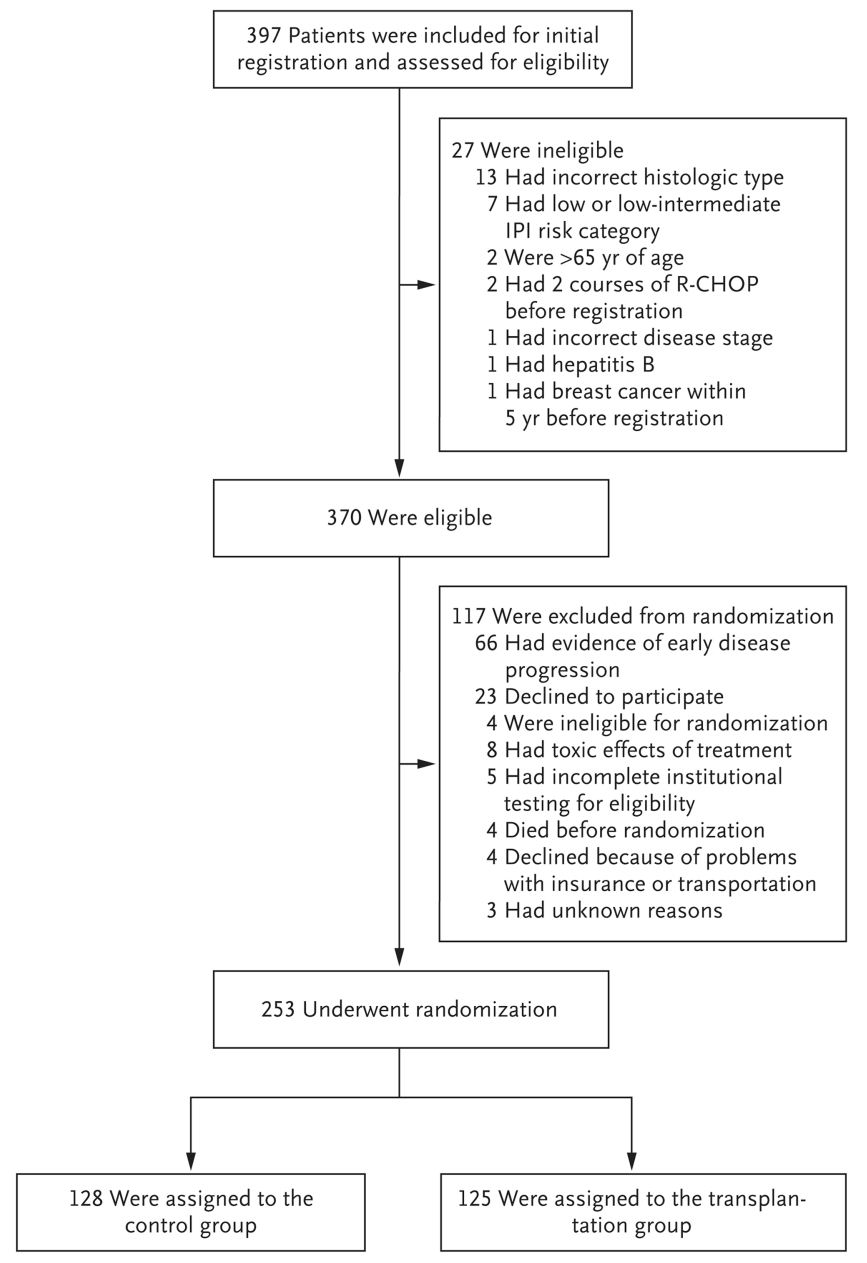

Figure 1. Registration of Patients and Randomization

IPI denotes International Prognostic Index, and R-CHOP rituximab plus cyclophosphamide, doxorubicin, vincristine, and prednisone. 
A

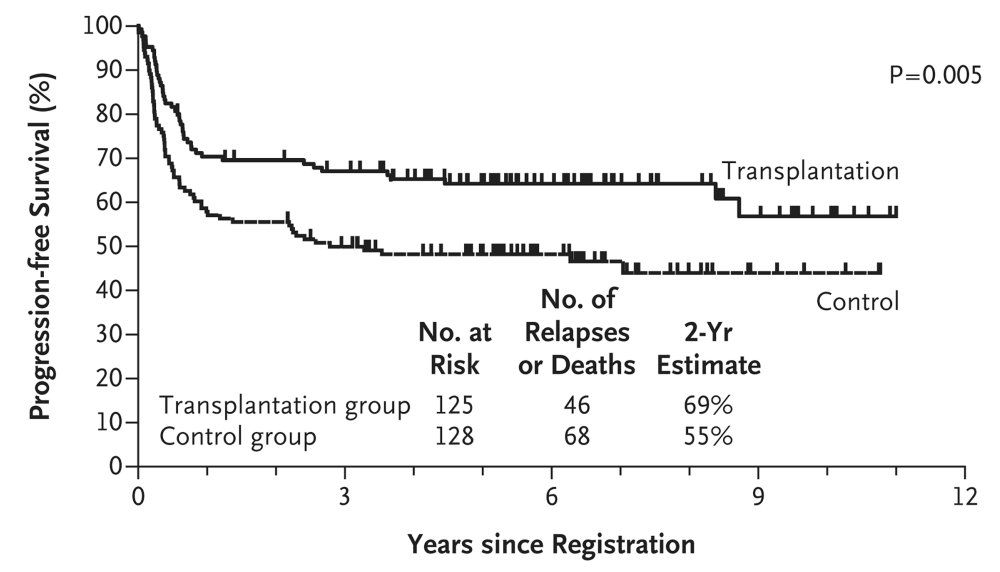

B

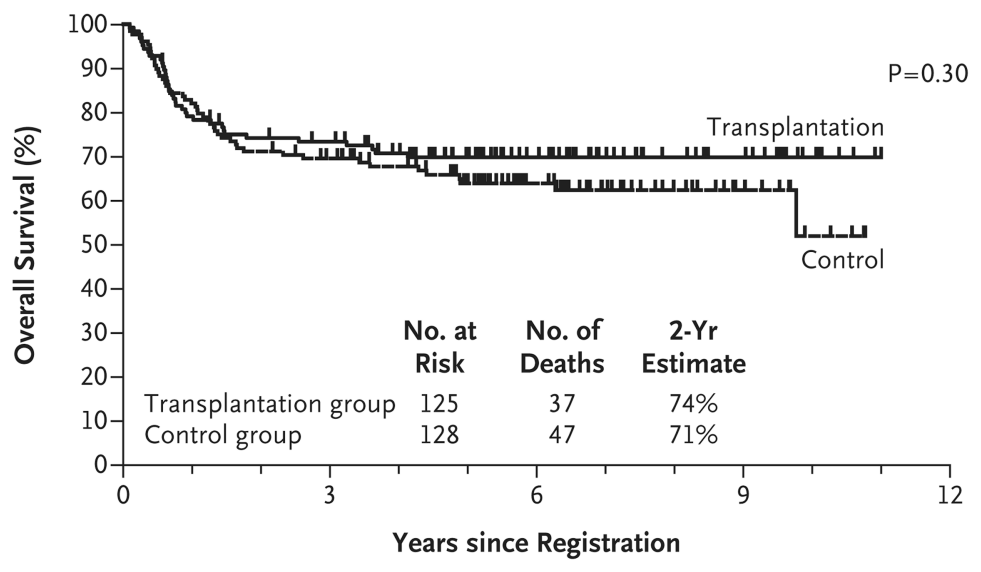

Figure 2. Survival Rates among All Eligible Patients Who Underwent Randomization Panel A shows rates of progression-free survival, and Panel B shows rates of overall survival. 

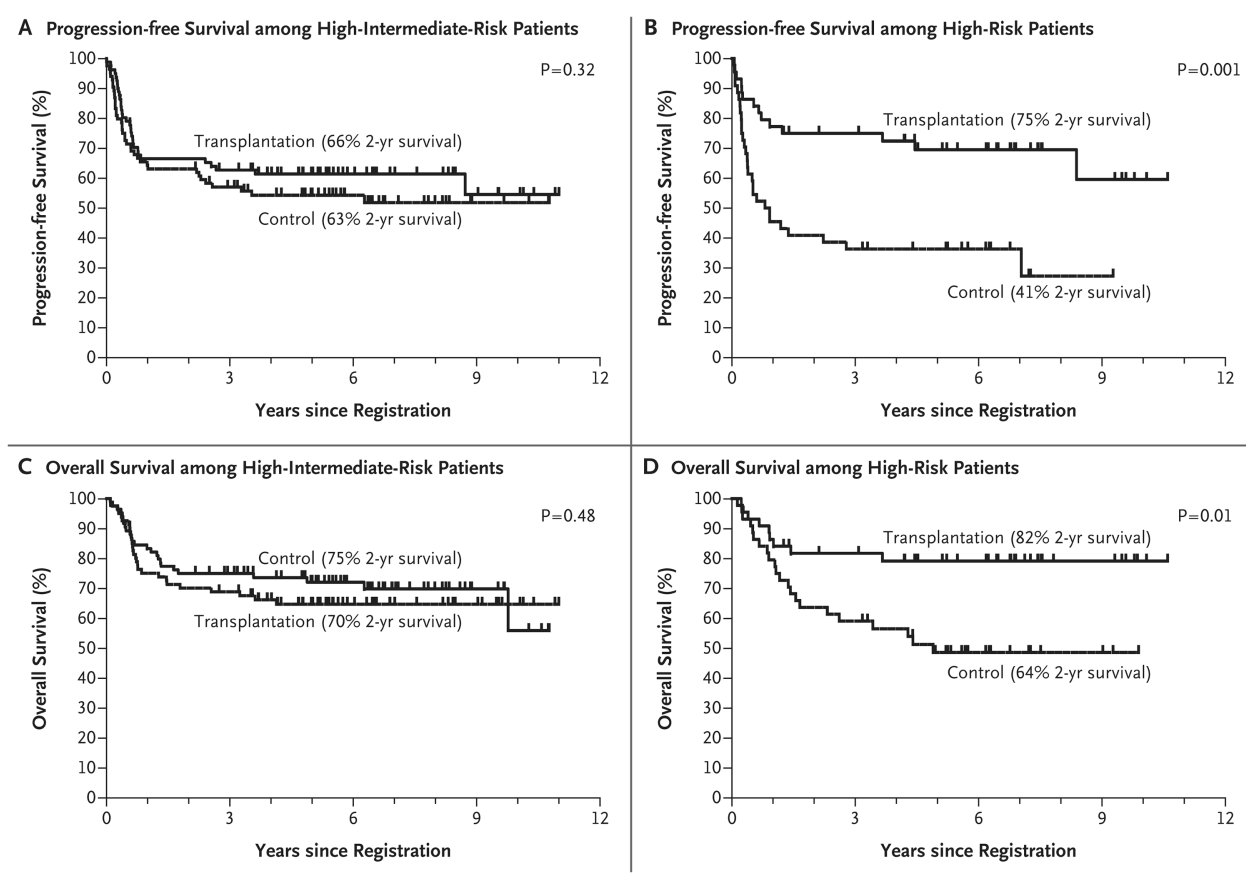

Figure 3.

Survival Rates among Eligible Patients Who Underwent Randomization, According to IPI Risk Category. 


\section{Table 1}

Characteristics of the 370 Patients Who Were Eligible for Randomization at Diagnosis.*

\begin{tabular}{|c|c|}
\hline Characteristic & Value \\
\hline \multicolumn{2}{|l|}{ Age - yr } \\
\hline Median & 51 \\
\hline Range & $18.3-65.9$ \\
\hline Male sex — no. $(\%)$ & $218(59)$ \\
\hline B-cell lymphoma - no. $(\%)^{\dagger}$ & $330(89)$ \\
\hline Diffuse large-B-cell lymphoma not otherwise specified & $248(67)$ \\
\hline Primary mediastinal large-B-cell lymphoma & $28(8)$ \\
\hline Unclassifiable, with features intermediate between diffuse large-B-cell lymphoma and Burkitt's lymphoma & $28(8)$ \\
\hline Follicular lymphoma, grade 3 & $16(4)$ \\
\hline Burkitt's lymphoma & $5(1)$ \\
\hline Other & $5(1)$ \\
\hline T-cell lymphoma - no. $(\%)^{\dagger}$ & $40(11)$ \\
\hline Peripheral T-cell lymphoma not otherwise specified & $20(5)$ \\
\hline Anaplastic large-cell lymphoma ${ }^{t}$ & $13(4)$ \\
\hline Angioimmunoblastic T-cell lymphoma & $7(2)$ \\
\hline \multicolumn{2}{|l|}{ Disease stage - no. $(\%)$} \\
\hline II, with bulky disease & $22(6)$ \\
\hline III & $116(31)$ \\
\hline IV & $232(63)$ \\
\hline Performance status $\geq 2-$ no. $(\%)^{\S}$ & $134(36)$ \\
\hline Elevated lactate dehydrogenase level — no. (\%) & $310(84)$ \\
\hline Bone marrow involvement - no. $(\%)$ & $83(22)$ \\
\hline \multicolumn{2}{|l|}{ Extranodal sites - no. (\%) } \\
\hline 0 & $126(34)$ \\
\hline 1 & $149(40)$ \\
\hline 22 & $95(26)$ \\
\hline B symptoms present — no. (\%) & $229(62)$ \\
\hline International Prognostic Index risk category: high risk - no. (\%) & $118(32)$ \\
\hline B-cell lymphoma treated with R-CHOP — no./total no.(\%) & $156 / 330(47)$ \\
\hline \multicolumn{2}{|l|}{ R-CHOP denotes rituximab plus cyclophosphamide, doxorubicin, vincristine, and prednisone. } \\
\hline \multicolumn{2}{|l|}{ The diagnosis was made on the basis of the World Health Organization classification. ${ }^{17}$} \\
\hline \multicolumn{2}{|l|}{ Patients who were positive or negative for anaplastic lymphoma kinase are included in this category. } \\
\hline \multicolumn{2}{|c|}{$\begin{array}{l}\S \text { Performance status was assessed according to the Eastern Cooperative Oncology Group scale, in which } 0 \text { indicates that the patient has no } \\
\text { symptoms; } 1 \text {, the patient has symptoms but is ambulatory; } 2 \text {, the patient is bedridden less than half the day; } 3 \text {, the patient is bedridden half the day } \\
\text { or longer; and } 4 \text {, the patient is chronically bedridden and requires assistance with activities of daily living. }{ }^{2}\end{array}$} \\
\hline
\end{tabular}


Table 2

Grade 3 and 4 Toxic Effects of Treatment.

\begin{tabular}{|lcr|}
\hline Toxic Effect & Transplantation Group (N= 125) & Control Group (N=128) \\
\hline & percent of patients & 13 \\
\hline Infection & 50 & 5 \\
\hline Gastrointestinal effects & 26 & 1 \\
\hline Metabolic effects & 13 & 2 \\
\hline Lung effects & 11 & 4 \\
\hline Cardiovascular effects & 10 & 5 \\
\hline Neurologic effects & 7 & 2 \\
\hline Dyspnea & 7 & 0 \\
\hline Hyperglycemia & 6 & 0 \\
\hline Hypoxia & 4 & \\
\hline Hepatic effects & 3 & \\
\hline
\end{tabular}

